University of Nebraska - Lincoln

DigitalCommons@University of Nebraska - Lincoln

October 1992

\title{
His and Hers: Male and Female Anatomy in Anatomy Texts for U.S. Medical Students, 1890-1989
}

\author{
Susan C. Lawrence \\ University of Nebraska - Lincoln, lawrence.578@osu.edu \\ Kae Bendixen \\ University of lowa
}

Follow this and additional works at: https://digitalcommons.unl.edu/historyfacpub

Part of the History Commons

Lawrence, Susan C. and Bendixen, Kae, "His and Hers: Male and Female Anatomy in Anatomy Texts for U.S. Medical Students, 1890-1989" (1992). Faculty Publications, Department of History. 35.

https://digitalcommons.unl.edu/historyfacpub/35

This Article is brought to you for free and open access by the History, Department of at DigitalCommons@University of Nebraska - Lincoln. It has been accepted for inclusion in Faculty Publications, Department of History by an authorized administrator of DigitalCommons@University of Nebraska - Lincoln. 


\title{
His and Hers: Male and Female Anatomy in Anatomy Texts for U.S. Medical Students, 1890-1989
}

\author{
Susan C. Lawrence ${ }^{1}$ and Kae Bendixen ${ }^{2}$ \\ ${ }^{1}$ Department of History and ${ }^{2}$ College of Medicine, \\ The University of Iowa, Iowa City, IA 52242
}

\begin{abstract}
Much recent work on gender has emphasized how ideas of male and female differences underlie cultural assumptions about appropriate social relations, behavior, institutions and knowledge. This study focuses on the specific ways that anatomy texts for medical students in the United States have presented male and female anatomy between 1890 and 1989, using both numerical data and analysis of textual examples from 31 texts. Despite public debates about gender representation, anatomy texts have generally remained consistent in how "the" human body has been depicted in this century. In illustrations, vocabulary and syntax, these texts primarily depict male anatomy as the norm or standard against which female structures are compared. Modern texts thus continue long-standing historical conventions in which male anatomy provides the basic model for "the" human body.
\end{abstract}

Keywords: medical education, anatomy, gender, textbooks, United States

One of the most fundamental anatomical categories is sex, the basic physical distinction(s) between male and female. Testicles or ovaries, penis or clitoris, are usually - but not always - straightforward markers of one sex or the other [1,2]. Being labeled "male" or "female," however, also carries cultural roles and assumptions. It is well known that such assumptions underlie social expectations of behavior, appropriate occupations and character. Yet concepts of "male" and "female" also influence the way that scientists view and describe the human body [3-5].

Of particular concern here is the way that anatomical texts used by medical students in the United States over the past century present "the" human body and how they represent gender. The first part of this study shows numerically that in the century from 1890-1989, anatomy texts have remained consistent in the disproportionate use of male figures or malespecific structures to illustrate and to describe human anatomy. Female bodies are primarily presented as variations on the male. They are used as exemplars of shared structures only in discussions of the bony pelvis. The proportion of non-gendered illustrations, those where sex is not defined by genitalia, secondary sex features, explicit notation in the caption, use of sex-specific terms in the caption or labels, or overt cultural signals (e.g. hairstyle), has also remained nearly constant. In their language and syntax, moreover, authors use female to male descriptive comparisons far more often than male to female ones.

The second part of our study focused on the language used to depict male and female anatomical features. The use of gender references in chapter headings and subheadings, male-specific terms in discussions of shared anatomical structures, and female to male homologies all combine to present the normal human body as male. For example, the clitoris is commonly described as "homologous with the penis in the male. Unlike the penis, the clitoris is not traversed by the urethra (original emphasis)." This text continues, "This small organ is composed of erectile tissue and, like the penis, is capable of enlargement upon tactile stimulation" [9]. We have found no text that reverses the homology, a switch that, on a literal level, is equally accurate: The penis is "homologous with the clitoris in the female. Unlike the clitoris, the penis is traversed by the urethra. This large organ is composed of erectile tissue and, like the clitoris, is capable of enlargement upon tactile stimulation." The direction of comparison is not socially symmetrical: clitoris (female variation) to penis (norm) is familiar to the point of "natural"; penis (male variation) to clitoris (norm) is peculiar to the point of amusement. Accuracy aside, this switch is not only odd because unexpected, but also because it is "wrong." Appealing to homology is not a useful way to present the penis. In our science and our culture, the penis is "obviously" a more complex and important organ than one described only in comparison to the clitoris. Yet why, then, does the original version appear so unremarkable for the clitoris?

In the $1890 \mathrm{~s}$, such male precedence in anatomy texts used in the United States could hardly be questioned. As historians have shown in other areas, male-centered conventions in medicine mirrored a society where most scientists, certainly most anatomists, were men, as were the vast majority of medical students. More important, such conventions also reflected and supported a culture where men held public office, political authority, and economic power, and women's primary functions were child-bearing and home-management, or those tasks 
requiring nurturing and domestic skills, such as nursing and teaching. From the 1970s and 1980s, however, in the context of an increasingly genderconscious society in the United States, one in which female patients outnumber male patients and entering medical school classes are on the order of onethird women, the persistence of male "dominated" anatomy texts has particular potency for transmitting the covert message that the female body depends upon the male body for its definition-anatomically and politically. That the choice of illustrations or syntax is not consciously designed to promote this point underscores the power of social assumptions at work in science.

In our analysis, the central point is certainly not that sex differences in anatomical structures are illusory social conventions. Rather, we present data, both numerical and textual, that reveal a remarkable consistency in the ways that gender differences have been portrayed in English-language texts. More significantly, these ways might seem to be, but are not, entirely free from cultural bias. Authors and illustrators today, as in the past, decide how to portray "the" body. In doing so they create an ideal that is the basis of medical students' understanding of normal human anatomy. Anatomical illustrations and language appear to be transparently descriptive, at once idealizations of and accurate representations of "nature." Most specific illustrations and textual reports in modern anatomy texts are indeed adequately factual depictions, taken individually. Yet, as our example of the penis as homologous to the clitoris suggests, the choice of "facts" about both sex-specific and sex-non-specific structures (what is included? what omitted?) and their presentation in language (large? small? male? female?) depend upon cultural assumptions and academic customs that are not imposed by "nature" onto the author or artist. To maintain that the anatomical texts in our study simply depict "the" human body is to deny the lenses with which we interpret nature and to burden it, in this case, with unacknowledged beliefs about gender.*

\section{MALE MODELS: SOURCES OF CONVENTION}

Scholars working on the historical and social construction of gender in Western culture recognize two very broad approaches to conceptualizing male and female anatomy: hierarchy and difference. Both of these basic models have long historical roots that have shaped how normal anatomical features are described and depicted. Both, moreover, treat female structures in terms of male anatomy $[10,11]$.

*For further evidence of the ways that gender has affected, and continues to effect, the construction of science, and discussion of the social implications of this bias, see Refs [6-8].
The first approach dominated ideas about the body from the classical Greeks to mid-seventeenth century anatomists. From this point of view, men a women, as humans, shared the same basic anatomical design and the same physiological processes. But, from the instant of conception, women were imperfect men: they were defined as humans who lacked the necessary anatomical structures and physiological balances to be "perfect." As Aristotle put it, "For the female is, as it were, a mutilated male" [12] Anatomical references and illustrations demonstrate how "natural" this hierarchy seemed to be. Throughout this period, anatomists discussed and depicted the female reproductive organs as modified male one The female was the male, turned outside in, retaining in her body the organs that, properly developed, were necessarily outside. Thus the ovaries were called "female testicles"; they had no separate name until the seventeenth century. The vagina was the penis; the uterus the scrotum. The clitoris, in this series of homologies, rarely had a name or, if it did, a function. In other areas, however, male and female shared the same organs and structures. Yet, with the deep cultural assumption that the male literally was the perfect human, pre-modern anatomists created the tradition that the body was a male body, particularly in the Renaissance explosion of anatomical illustrations. Using male bodies to depict the muscles, skeleton and internal organs, and referring to women only for the female reproductive system and external body type, became a widespread convention, the de facto norm, artistically and textually.

In contrast, from the late-seventeenth century anatomists began to see, and to present, a distinctly "female" anatomy. In this second model, women were not simply inferior men, but quite different creatures altogether, from their skeletons to their nervous systems. As one physician put it in 1775, "The essence of sex is not confined to a single organ but extends, through more or less perceptible nuances, into every part" $[10$, p. 51]. When describing this newly nuanced female anatomy, however, anatomists explicitly did so in comparison to the male norm already well established. Thus in both illustrations and text, authors regularly referred to female parts as smaller than those in the male, lacking male features, or, more elusively, as decidely feminine. Consider the following passage from J. J. Sachs, a German physician writing in 1830: "The male body expresses, positive strength, sharpening male understanding and independence, and equipping men for life in the State, in the arts and sciences. The female body expresses womanly softness and feeling. The roomy pelvis determines women for motherhood. The weak, soft members and delicate skin are witness of woman's narrower sphere of activity, of home-bodiness, and peaceful family life" [10, p. 69]. As noted here, the only area where women "exceeded" men was in the size of their pelvis. This example also illustrates that positive comments about female structures were 
nearly always made to highlight women's capacity for motherhood and - as a logical correlate-for a domestic role [13].

At the end of the nineteenth century, these two approaches to gender differences were well established. Anatomy texts regularly used male bodies to illustrate "the" body, even for non sex-specific features. Authors routinely described female structures as variations on male ones, categorized as "weaker," "smaller," or "less than" the male counterpart. Only with the pelvis did the female provide the standard, as in the quotation from 1830, with its design for childbirth. Familiarity with this historical analysis, and our own experiences in gross anatomy courses for medical students, led us to our study: examining the depictions of male and female in anatomy texts published over the last century.

\section{TEXTS AND METHODS}

The 31 textbooks chosen for this study were all intended for use in gross anatomy courses for medical students in the United States. Telephone and personal interviews with a number of anatomy instructors at major medical schools in the United States provided titles for an initial list of texts assigned currently or in the past three decades. The University of Iowa's Hardin Library for the Health Sciences contained the other books selected. These were chosen for their text-book formats, self-proclaimed medical student audiences, and, in several cases, because they were editions of well-known texts, such as Grant's and Gray's anatomies. When we evaluated the data, we divided the books into 6 chronological groups according to their publication dates, 1890-1919, 19201949, 1950-1959, 1960-1969, 1970-1979, and 1980-1989 (Table I). We primarily used averages from each set in order to display the data in concise form and to reveal possible changes over time.

Three distinct sections in each book were examined: the thorax, the abdomen, and the pelvis and perineum. We chose these sections because they contain a broad range of sex-non-specific and sex-specific features that allowed us to survey diverse types of gender representation. In the thorax, all features but the female breast are common to both males and females. Similarly, the abdomen primarily contains non-sex-specific structures, yet has a number of sex-specific parts, such as the contents of the inguinal canal. Discussion of the pelvis and perineum, in contrast, include external genitalia and internal reproductive organs that are quite sex-specific, as well as many common features, such as the urinary bladder and anus.

In the textbooks with regional formats, we examined the appropriate chapters or subsections for these areas. In books arranged systematically, we selected the subsections in which these areas were covered. In addition to the written text, all illustrations, photographs, X-rays, Computerized Tomographies (CTs) and Magnetic Resonance Images (MRIs) were examined. We report only on drawn illustrations, however, because the alternate images varied considerably over time, comprised a very small proportion of the total number of images for texts that used them, and do not have as much freedom of gender-choice

Table 1. Texts sampled, 1890-1989. All texts were published in the United States

\section{Title}

[Gray's] Anatomy (13th edn)

Morris's Human Anatomy (4th edn)

Quoin's Elements of Anatomy (11th edn)

Human Anatomy (8th edn)

Cunningham's Textbook of Anatomy (7th edn)

A Method of Anatomy (4th edn)

A Method of Anatomy (5th edn)

Morris' Human Anatomy (llth edn)

[Gray's] Anatomy (26th edn)

Concise Anatomy (2nd edn)

Anatomy of the Human Body (1st edn)

Anatomy: A Regional Study (1st edn)

Essentials of Human Anatomy (2nd edn)

Anatomy: A Regional Study (2nd edn)

Grant's Method of Anatomy (7th edn)

A Textbook of Human Anatomy (1st edn)

Reconstructive Anatomy (1st edn)

Essentials of Human Anatomy (4th edn)

Basic Human Anatomy (1st edn)

Synopsis of Gross Anatomy (2nd edn)

Clinical Anatomy for Medical Students (1st edn)

Textbook of Anatomy (3rd edn)

Essential Anatomy (2nd edn)

A Textbook of Human Anatomy (2nd edn)

Grant's Method of Anatomy (10th edn)

Clinical Anatomy for Medical Students (2nd edn)

An Introduction to Human Anatomy (1st edn)

Anatomy as a Basis for Clinical Medicine (1st edn)

Clinically Oriented Anatomy (2nd edn)

Essential Anatomy (4th edn)

Clinical Anatomy (1st edn)

\begin{tabular}{ll} 
Editor/Author & Year \\
Pick & 1893 \\
Morris et al. & 1907 \\
Schafer et al. & 1908 \\
Piersol & 1923 \\
Brash et al. & 1937 \\
Grant & 1948 \\
Grant & 1952 \\
Schaeffer & 1953 \\
Goss & 1954 \\
Edwards & 1956 \\
Lockhart et al. & 1959 \\
Gardner et al. & 1960 \\
Woodburne & 1961 \\
Gardner et al. & 1963 \\
Grant, Basmajian & 1965 \\
Crafts & 1966 \\
Arnold & 1968 \\
Woodburne & 1969 \\
Tobin & 1972 \\
Christiansen & 1972 \\
Snell & 1973 \\
Hollinshead & 1974 \\
Lumley et al. & 1975 \\
Crafts & 1979 \\
Basmajian & 1980 \\
Snell & 1981 \\
Green, Silver & 1981 \\
Hall-Craggs & 1985 \\
Moore & 1985 \\
Lumley et al. & 1987 \\
Lindner & 1989 \\
& \\
\hline
\end{tabular}


as drawn structures [3, p. 415]. In order to examine gender representations in illustrations and text objectively, we devised tally-sheets to record the data for each section (thorax, abdomen, pelvis/perineum) of each book, as described in points 1, 2, and 3 below. The fourth area (4) could not be quantified, and for this we focused on transcribing numerous pertinent examples.

\subsection{The sex of the illustration-male, female, or non- gendered-and how that information was conveyed}

The illustration was categorized as male or female as long as it had one or more of the following gender indicators, each of which we noted: mention of the sex in the caption (i.e. "Cross section of female pelvis"), mention of a sex-specific feature in the caption (i.e. "ductus deferens"), a sex-specific feature in the illustration itself, whether labelled or unlabelled (i.e. rectovesical pouch), inclusion of genitalia, secondary sexual characteristics (i.e. breasts or hair distribution), stereotypical figure, or stereotypical hairstyles and/or clothing. When a text used a particular stereotypical figure for male (broad shoulders, narrow pelvis) or female (narrow shoulders, broad pelvis), it always occurred first with a gender label and/ or sex-specific anatomical features. We categorized later figure(s) with the same outlines according to the previously identified gender. The last category, the social hints suggesting man or woman, in fact never stood alone as the only gender determinant. Finally, individual figures with separate illustrations for male and female were tallied as one of each. Illustrations without any of these gender markers and those that combined male and female features into a single illustration, were classified as non-gendered.

\subsection{The amount of text space devoted to discussion of sex-specific features and variations}

We calculated one or more index numbers for each text consisting of the average number of letters and spaces per line of each type-style. We used this to multiply the number of lines devoted to male-specific and female-specific text, in order to get ratios for relative text space that could be compared across books with quite different formats.

\subsection{Specific comparisons in the text of male and fe- male anatomy}

We used two categories for this tally. First, we noted the direction of anatomical comparison: female compared to male (e.g. clitoris as homologue of the penis) or male compared to female (penis as homologue of the clitoris). Second, we tallied the authors' use of parentheses to give an alternate, sex-specific

* The three instances are: (1) in a discussion of portions of the levator ani, Crafts used "pubovaginal (levator prostatae)" [14]; (2 \& 3) Woodburne, covering the distribution of the hypogastric nerves, noted that "they are in the base of the rectouterine fold in the female (or the rectovesical fold in the male)" $[15,16]$. term, also noting the direction of comparison. For example "testicular (ovarian) artery" follows the "male (female) pattern, while 'round ligament (spermatic cord)" shows the "female (male)" configuration.

2.4. The illustrations and language employed for describing sexual differences and sex-specific/sex-nonspecific structures

During the quantitative survey, we noted and frequently transcribed examples of male-centered, female-centered, and non-gendered illustrations, vocabulary, and syntax. For example, we recorded the use of adjectives, such as the "small clitoris," and descriptions of comparisons and implied "purpose," such as childbearing for the pelvis. This process provided material for our analysis of specifically how illustrations and language depict gender similarities and differences. Close examination of illustrations and extracts delineate and refine what it means, in practice, for anatomy texts to be culturally gendered.

\section{NUMERICAL RESULTS}

Figure 1 shows the collective results, in percentages, for all the illustrations categorized as female, male, and non-gendered, with the total number of illustrations for each period (total $N=6,196$ ). In all groups, male figures steadily outnumbered female figures. Despite variations among the categories over time and between regions, moreover, the ratio of male illustrations to female ones remained almost constant, at nearly two and a half to one (mean = 2.43 , range $2.2-2.5, \mathrm{SD}=0.11,4.5 \%$ of the mean) over the century. The ratio of male/female illustrations calculated for each period appears in the first bar set of Figure 2. We computed two other ratios to evaluate the textual data, which appear as the second and third bar sets in Figure 2. Note that equal representation would result in ratio of 1.0, highlighted by the heavier line. The second bar set shows the proportion of male-specific text space to female-specific text space. This ratio decreased gradually over the century, from a high of 1.69 for the 1890-1919 sample to a low of 1.23 for that from 1980-1989 (mean $=1.47$, range $1.69-1.23, \mathrm{SD}=0.16,10.9 \%$ of the mean). The third set of bars presents the ratio of textual comparisons for each period: the average number of female to male comparisons divided by the average number of male to female comparisons. This set contains considerable variation (mean $=7.9$, range $5.5-10.1, \mathrm{SD}=1.7,21.5 \%$ of the mean), yet consistently shows high values for the index gauging male as "norm" and female as variation. The direction of parenthetical expressions, male (female) compared to female (male), further reveals the textual emphasis on male structures. Table 2 presents the average occurrences for each time period. In our entire sample the authors and editors chose to use the female structure as the primary one, with the male term in parentheses, only three times, one of which repeated the text from a previous edition.* 


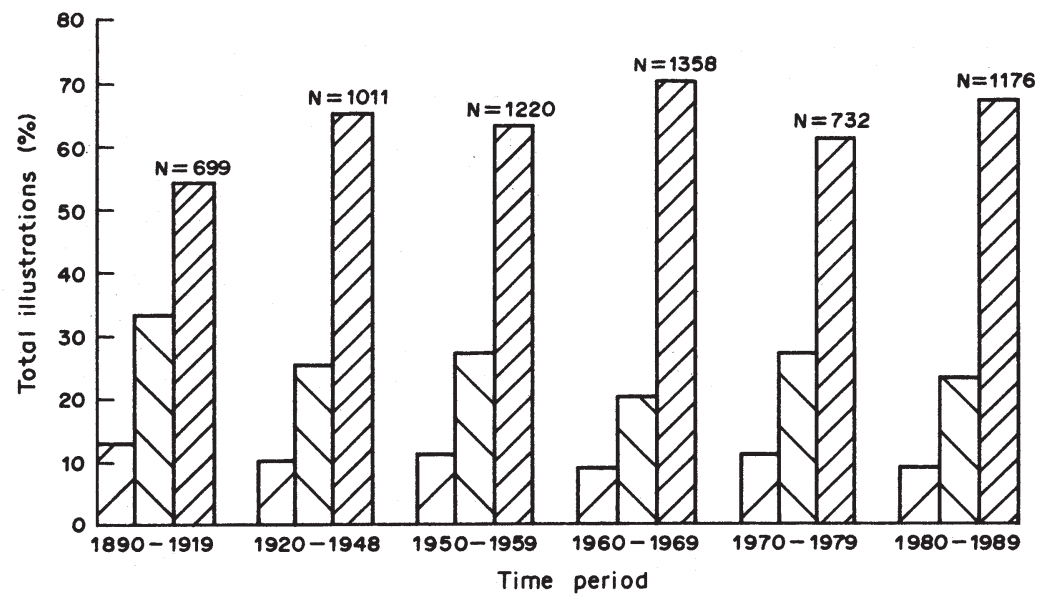

$\square$ Female (\%)

$\Delta$ Male $(\%)$

$2{ }_{\text {Non-gendered }(\%)}$

Figure 1. This graph shows the sample size for each chronological period $(N=)$, with the percentage of female, male and non-gendered illustrations displayed in each bar set. In all samples, male figures outnumbered female figures approximately $2.5: 1$ (mean $=2.43$, range $2.2-2.5, \mathrm{SD}=0.11,4.5 \%$ of the mean).

\section{DISCUSSION: ILLUSTRATIONS, LANGUAGE AND GENDER}

The quantitative survey indicates that authors and editors have made few changes in their choices of anatomical illustrations and textual conventions. While these numbers display the relatively high male to female ratios for figures, texts and directional comparisons, they cannot convey how either drawings or language establish the male as the anatomical standard from which the female is derived. Only specific analysis of the illustrations and text reveals the way that this implied hierarchy works. In this section, therefore, we focus on particular examples drawn from the books in our study.

Authors and editors included male illustrations to demonstrate anatomical features common to both sexes far more frequently than female illustrations. Woodburne's 1969 Essentials of Human Anatomy contains Figure 3, for example, to depict "the arteries

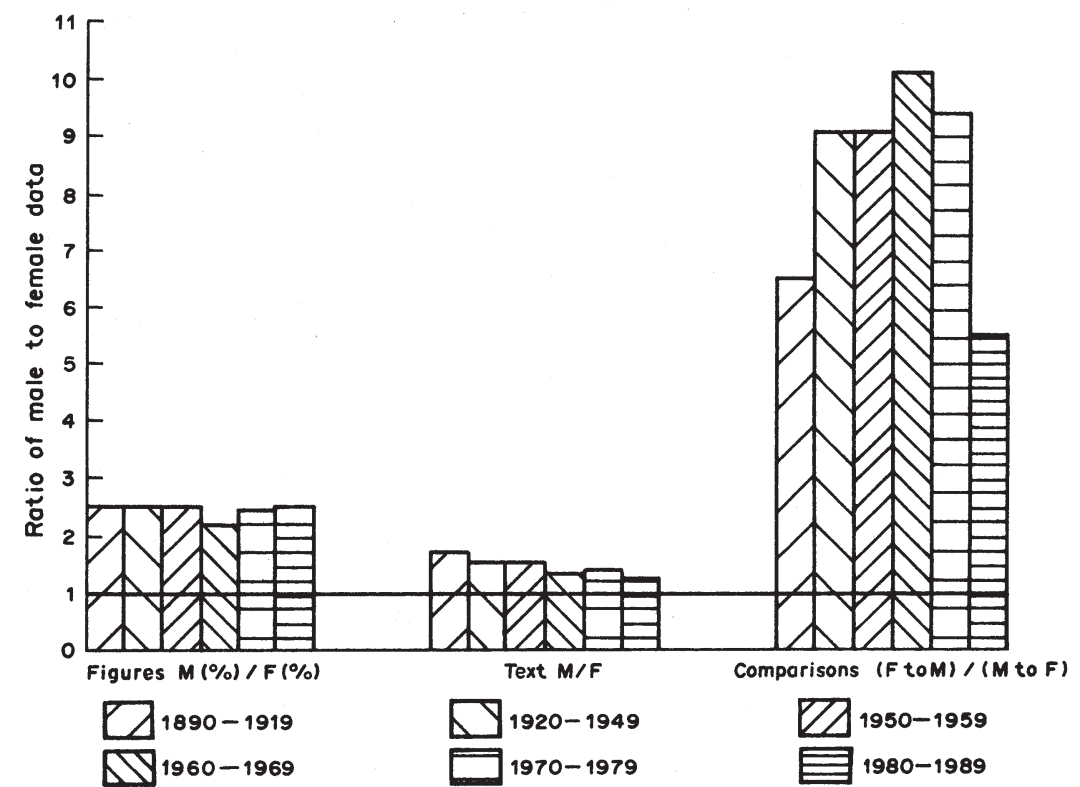

Figure 2. This graph displays our quantitative results in terms of ratios between male-centered and female-centered illustrations and text for each chronological period. The heavy line at 1.0 represents the point of equal representation or directionality of comparison. The first set compares the percentage of male to female figures, as shown in Figure 1. The second set shows the ratio of text space devoted to discussions of male anatomy to that for female anatomy. The third set of bars presents the ratio of textual comparisons for each period: the average number of female to male comparisons divided by the average number of male to female comparisons. 
Table 2. The average number of times male and female alternate structures were presented in parenthetical order Male (Female) and Female (Male) in the sampled texts for each time period

\begin{tabular}{lcc}
\hline & Male (Female) & Female (Male) \\
$N=$ & 356 & 3 \\
\hline $1890-1919$ & 1.0 & 0.0 \\
$1920-1949$ & 18.3 & 0.0 \\
$1950-1959$ & 5.4 & 0.0 \\
$1960-1969$ & 26.5 & 0.3 \\
$1970-1979$ & 4.9 & 0.2 \\
$1980-1989$ & 5.3 & 0.0 \\
Mean & 10.2 & 0.08 \\
\hline
\end{tabular}

of the anterolateral portion of the abdominal wall."* In this case the sketched-in penis does not add functional information to the reader's understanding of the abdominal wall; it only serves to make the torso male. Slightly more subtle is the practice shown in Figure 4. Here a common feature, "the posterior abdominal wall," is presented with a caption that does not specify male or female. Yet in the illustration itself, the male-specific testicular arteries and veins appear with labels. Note, too, that the pelvic brim shows only the urinary bladder and rectum, another male-specific feature. Such details are anatomically correct for a male drawing, but are not part of "the" human body. Both figures depict an idealized anatomy in the obvious sense that neither are supposed to be "real" individuals; they are useful abstractions of the relevant parts. Making these figures male, however, either compromises their claim to be representations of a universal anatomical feature, or it creates an anatomical ideal in the form of the male body.

Compared to illustrations, text is undoubtedly easier to create and to modify in anatomy books. ${ }^{\dagger}$ When patterns of syntax, terminology and directional comparisons remain consistent over time, authors and editors presumably find these conventions satisfactory, even pedagogically beneficial. In Grant's 1952 edition of A Method of Human Anatomy, 5th edn, for example, he began his comparison of the male and female pelvis with the sub-section "Features dependent on the fact that woman is the weaker vessel" [18, p. 368]; In Basmajian's 1980 edition of Grant's Anatomy, this became "Features dependent on the fact that woman is smaller and weaker" [17]. Basmajian deleted the oldfashioned "vessel," showing that he indeed changed the language in this part of the text. Yet the directional comparison of female to male remains, encapsulated in both Grant's and Basmajian's use of "weaker."

Throughout our sample, the organization an language employed present male anatomy as the norm which must be understood before the student can comprehend female structures. Four ways that authors and editors depict male-as-norm and femaleas-variation are particularly clear-cut in these text (1) chapter and section organization; (2) omission of any reference to female terms or structures; (3) directional comparisons of size, form and function; and (4) visualizing the female as an altered male.

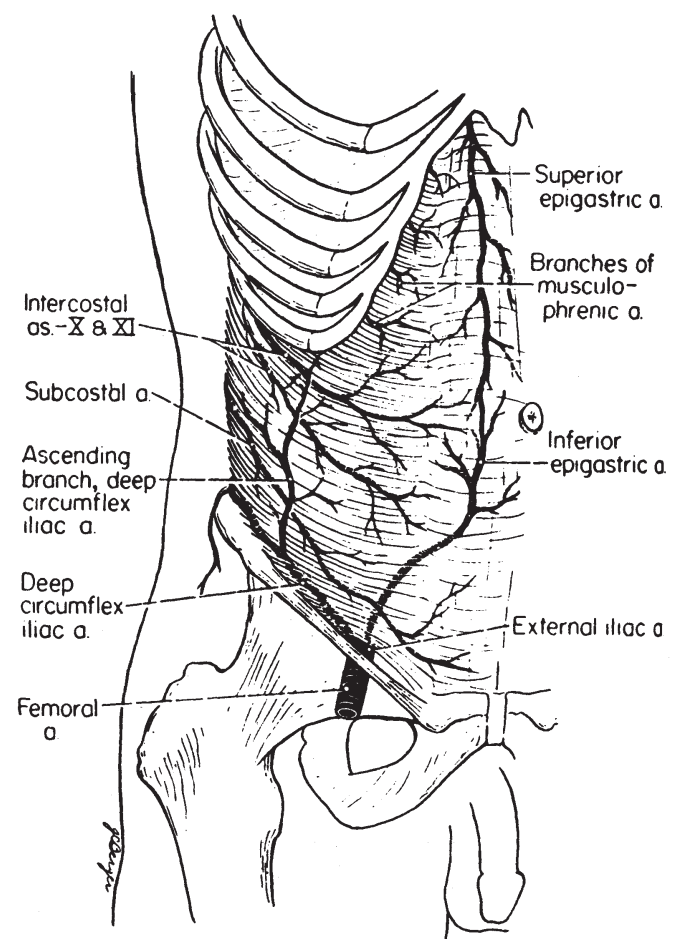

Figure 3. Source: R. T. Woodburne, Essentials of Human Anatomy, p. 372. Oxford University Press, New York, 1969. Reprinted by permission.

Chapter or section headings frequently demarcate the female as a "different" human type compared the standard (male) human. Morris' 1907 Human Anatomy, for example, has a section called "The Perineum and Genitals" followed by a section on "Female Genital Organs" [pp. 1308, 1317]. Similarly, in the 1980 Grant's Method of Anatomy, Basmajian kept the familiar sections entitled "The Perineum" and "The Female Perineum." Hall-Craggs labeled two equivalent sections in his chapter on the abdomen "The Inguinal Region" and "Herniae." "The Inguinal Region in the Female," the only reference to the female in subsection titles, appeared under "Herniae" (malformations), however, not under "The Inguinal Region" (normal anatomy). "The Inguinal Region" under this organization covered only male-specific features. In his Synopsis of Gross Anatomy, 2nd edn, 1972, Christiansen used non-gendered chapter titles, such as "Perineum" and "Pelvis." In the subsection called "Male Pelvic Organs," however, he included sections

* The same illustration appears on p. 420 of R. T. Woodburne and W. E. Burkel, Essentials of Human Anatomy, 8th edn. Oxford University Press, New York, 1988.

$\dagger$ The use of drawings and plates from earlier editions or other sources might partly account for the persistence of male-centered illustrations [13, 5], since illustrations are time-consuming and expensive to produce. Yet the ratio of male to female illustrations was still 2.3 to 1 in Anatomy as a Basis for Clinical Medicine, 1st edn, 1985, where HallCraggs stressed that all of the figures were newly drawn $(N$ $=164 ; 67 \%$ non-gendered, $23 \%$ male, $10 \%$ female). 


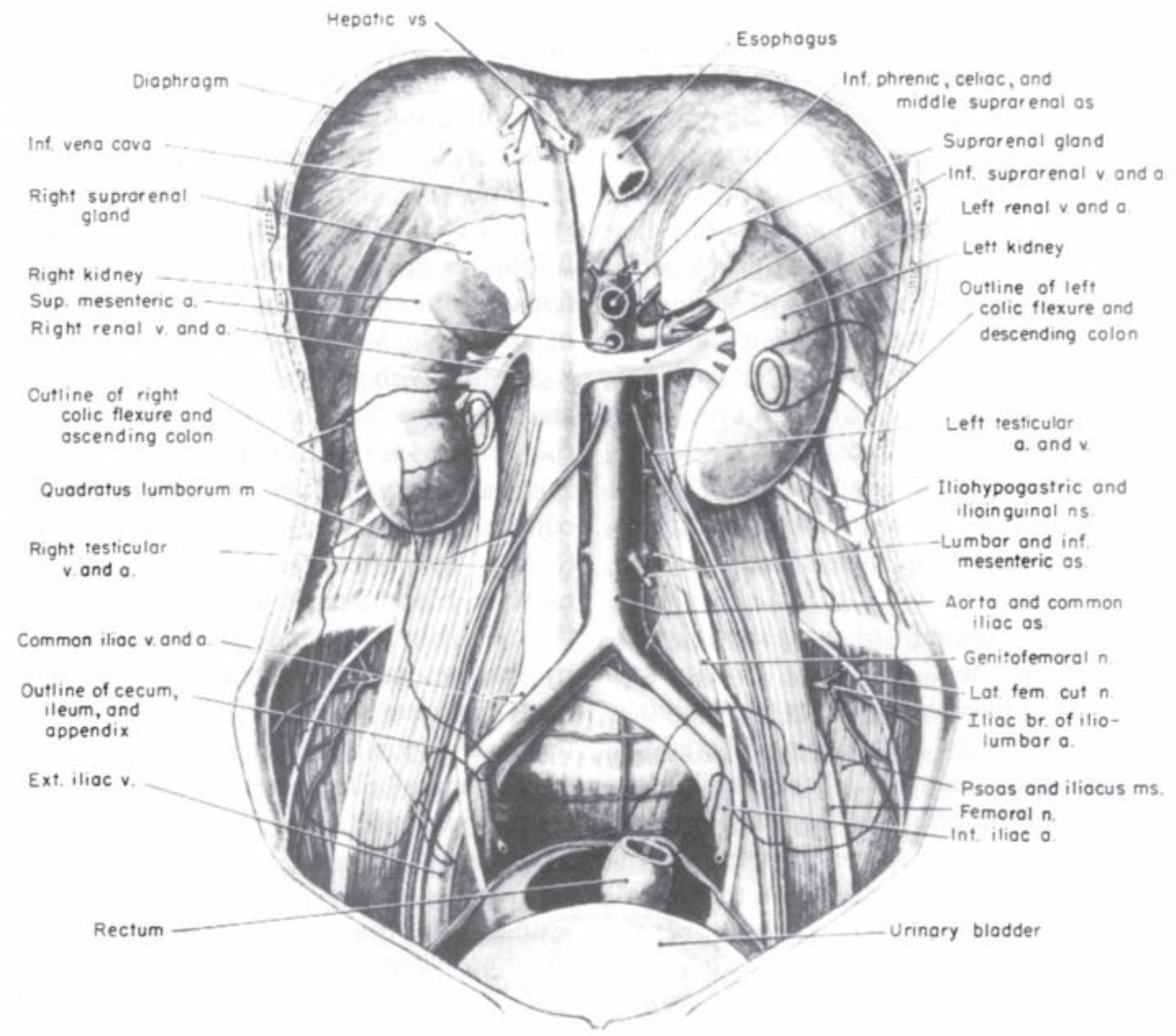

Figure 4. Source: R. C. Crafts, A Textbook of Human Anatomy, 2nd edn, p. 260. John Wiley \& Sons, New York, 1979. Reprinted with permission Churchill Livingstone.

for the urinary bladder and urethra in which he briefly mentioned the relationship between the bladder, urethra and surrounding pelvic viscera in the female. Students thus study the bladder and urethra in the female in the context of "male pelvic organs," not in the following sub-section, which is devoted only to "Female Reproductive Organs."

The convention of discussing male structures under a "the" heading, and female ones as specifically "female" occurred throughout our samples. In most cases, moreover, the coverage of "the" anatomical region or the particularly male section (as with "Male Pelvic Organs") preceded the subsection set aside for the female variation. Both in order and in organization, students first study male anatomy: "If you have familiarized yourself with the details of the male perineum, you will not have difficulty in appreciating the structure of the female perineum" [18]. Indeed, if "you" have not, you must go back and do so if the female perineum is to be intelligible.

Authors and editors have also discussed shared anatomical regions in terms of male structures without referring to the female at all. Texts after 1960 are not always more precise than Cunningham's 1937 Textbook of Anatomy, which included the remark that "in the child at birth the peritoneum extends down to the base of the prostate" [p. 6]. The 1963 Anatomy: a
Regional Study of Human Structure, for example, described "the" abdominal wall using references to the penis, scrotum and spermatic cord, without female qualifiers [19; see also 17, p. 125; 20-23]. Similarly, stating that "The inguinal canal with its inlet (abdominal inguinal ring) and its outlet (subcutaneous inguinal ring) result from the descent of the testes from the abdominal cavity into the scrotum" is certainly accurate for the male, although "male" is not specified here [24]. It does not, however, explain the formation of "the" inguinal canal and its contents, the round ligament, in the female.

Male-centered chapter organization or male-only descriptions are, on a large scale, examples of directional comparisons where male anatomy sets the standard to which the female is implicitly contrasted. In our sample, as discussed above, most comparative statements and parenthetical alternate terms compare the female to the male structure, either directly or by placing the female term in parentheses after the male expression (see Figure 2, Table 2). There are numerous ways that this syntactical pattern appears in anatomy texts, especially with phrases such as "in contrast to the male" in descriptions of female structures [25], Slightly less conspicuous are size comparisons and reliance on appeals to homologies. Authors who provide numerical estimates of mean weights or sizes 
do so first for male organs and then offer either the female size estimate or vague comments such as, for the heart, "the volume is somewhat less in females" $[19$, p. 401; see also pp. 466-467; 20, pp. 798, 1224, $1323 ; 26]$. Throughout the century, texts usually presented impressionistic size comparisons in terms of the female or female structure as "smaller," "feebler," "weaker," or "less developed." Finally, even using "absolute" adjectives in seemingly objective descriptions of size entails implicit comparisons to other structures. Calling the ossicles of the inner ear "tiny" or "small" is effective only with the understood contrast with most human bones. Describing the clitoris as "small" or "diminutive" similarly depends upon a comparison, sometimes explicit and sometimes inferred, with its male homologue, the penis [23, p. 155; 27].

One reason that the amount of male-specific text exceeds female-specific text (see Figure 2) rests on the convenience of implied homologies. In Morris's Human Anatomy, 11th edn, for example, the editor used 10 lines of compact text to detail the distribution of the dorsal nerve of the penis; he then noted, using two lines of text, that "The dorsal nerve of the clitoris [n. dorsalis clitoridis] is much smaller than the dorsal nerve of the penis to which it corresponds. It is distributed to the clitoris" [28]. Similarly, in his introductory discussion of "The Spermatic Cord," Hall-Craggs stated that "in the female the round ligament follows a similar course but terminates in the fibrofatty tissue of the labium majus" [29]. In these cases the unstated homologies between the penis and clitoris, the spermatic cord and round ligament, and between the scrotum and labium majus, seem to make an itemized discussion of the female structure unnecessary, despite the fact that several of the landmarks given for the "similar course" or distribution are male-specific. Authors also use homologies to emphasize the direction of subsequent comparisons. Thus, "the superficial structures of the urogenital triangle are the penis and the scrotum in the male and the homologous external genital parts in the female" [15, p. 460]. Instead of naming the female "parts," the author establishes their connection to the male genitals.

Using parentheses to provide the female names for male parts discussed in the main text further portrays the female as a (secondary) variation. The technique itself can convey accurate information in compact prose: "The external pudendal veins receive the superficial dorsal vein of the penis (or the clitoris) and the subcutaneous veins of the scrotum (or the labium majus)" [16, p. 362]. What reinforces the pattern of male-as-norm and female-as-variation, is not the parentheses per se, but the nearly universal use of male (female) as the conventional order. Authors and editors periodically end up with inconsistent, and sometimes inaccurate, accounts, moreover, when they add the appropriate female term in some places, but not others. When detailing the dorsal nerve of the penis, for example, Woodburne noted "continuing forward in company with the dorsal artery of the penis, the nerve lies on the dorsum of the penis (or clitoris)" [16, p. 466]. Similarly. Grant and Basmajian declared "Varicocele, i.e. varicose testicular veins, is a condition almost restricted to the left testicular (or ovarian) vein." [30]. In this example, inserting "ovarian" recognizes the female name for the testicular vein, but in the context of varicocele, a male-specific disorder.

Starting with the male as the standard of "normal" anatomy also leads authors and editors to describe the female as an altered male. In Anatomy: A Regional Study of Human Structure, for example, editors introduced the urogenital triangle "in the female" by noting that "the fasciae, fascial spaces, muscles, blood vessels and nerves resemble those of the male, but their anatomy is modified considerably by the presence of the genital organs" [25, p. 624]. Such phrasing prepares the reader first to visual the male region and then to change the image as the female genitalia are inserted. Some authors make this process explicit:

Imagine that the bulb in the male perineum is divider longitudinally so as to form the bilateral bulb of the vestibule. This consists of erectile tissue and is covered by the same bulbospongiousus muscle as we described in the male but the bulb is now split into two halves [31].

When authors use verbs that ask the reader perform an action on a mental image that transform a structure from male to female, they write as though something "happens." In this presumably heuristic process, their language offers inaccurate and misleading anatomical information if taken at all literally. "In the female the uterus and its broad ligament divide the rectovesical fossa into vesico-uterine and rectouterine fossae" [30, p. 236, our emphasis; 32]. The female does not have a rectovesical fossa; nor does the male have vesico-uterine and recto-uterine fossae from which the uterus and broad ligament have been removed. Authors and editors use similar transformative language when discussing how females differ from males in their common embryological morphology. The female genitalia stand as "comparable to that in a very early stage of development in the male" $[27$, p. 743]. From this perspective however, structures in the female are consistently presented as those that "fail" to develop, once again in contrast with the adult male form [24, p. 445; 28, p. 1566].

In all the anatomy textbooks in our survey, illustrations, syntax and language worked together in various ways to portray male anatomy as the standard to which female structures were compared, or from which they were derived, either literally or metaphorically. Yet certainly not all illustrations and terms were either male or female; the dichotomy hardly so obvious or absolute. As noted in the survey (see Figure 1), for example, an average of $63 \%$ of the illustrations were non-gendered. These primarily depicted 
structures in non-sex-specific regions (e.g. upper abdomen, thoracic cavity) and where position or scale clearly made sex-indicators immaterial (e.g. lower intercostal spaces, bronchial trees, structure of the kidney). It was far more unusual, however, for authors and editors to replace sex-specific terms with nongendered ones, use female torsos, or offer male to female homologies, when presenting "normal" shared anatomy. Such instances show deliberate alternatives to the conventional usages that we have discussed. When varying the male-as-norm, female-as-variation pattern, authors most frequently offered non-gendered terms in place of sex-specific ones: "pelvic viscera" for bladder or bladder and uterus [33]; "external genitalia," where appropriate, for penis-and-clitoris and/or labium majus-and-scrotum [23, p. 127; 33]. In a few cases, authors presented an area frequently given in male-specific terms, such as the inguinal canal, entirely by using both male and female terms and descriptions side by side [34]. Some texts included non-gendered torsos, that is, with no external genitalia or breasts, to illustrate shared structures [23, p. 89]. One recent author, in contrast, used paired male and female torso outlines when drawing common areas, such as the abdominal viscera, abdominal wall lymphatics and nerve supply to the anterolateral abdominal wall [35]. In rare instances, moreover, anatomists presented a male structure as homologous to a female one, notably the prostatic utricle, the "homo$\log [\mathrm{sic}]$ of the vagina in the female" $[35$, p. $510 ; 14$, p. $303 ; 22$, p. 143].

\section{CONCLUSION}

From our study of 31 anatomy textbooks published in the United States over the last century, we found that modern anatomy texts have continued long-standing historical traditions. Now, as in the past, male anatomy serves as a standard to which female anatomy is compared. Twentieth-century anatomists perpetuate the conventions setting the male as the central model of human anatomy. Choosing male illustrations for non-sex specific features, organizing chapters with "the [male]" headings distinct from "the female" sections, using explicit or implicit directional comparisons of female to male structures, placing female terms in parentheses, and directing readers to visualize female regions as altered male ones, all maintain an anatomical hierarchy: male, then female; male as norm, female as different.

Underlying the disproportionate use of male-centered anatomy, shown particularly in our numerical data, is the sometimes overt and sometimes subtle use of illustrations, syntax and vocabulary that makes it impossible to learn female anatomy without first learning male anatomy. It is this overall female-depends-upon-male directionality that discloses what it means for these ostensibly objective, scientific texts to be culturally gendered. The few examples of non- gendered terms and female-gendered illustrations showing "normal," shared anatomy, make this clear. As these options also convey accurate information, they demonstrate that male-centered texts are not simple representations of "nature," but are put together according to professional and social assumptions about what constitutes "the" human body.

Anatomists have produced a powerful and authoritative science of the human structure that is vital to advanced work in various areas of medical research and medical practice. Seeing how the normal human body is routinely depicted as male, or malecentered, in illustrations and language hardly invalidates mainstream anatomical knowledge. Yet becoming aware of how much "his" anatomy dominates "hers" in texts designed for medical students exposes unnecessary genitalia, useless comparisons, careless inaccuracies and errors. More important, this process reveals how far Western culture is from creating a non-gendered human anatomy, one from which both male and female emerge as equally significant and intriguing variations, and with which the medical student can comfortably "visualize his [sic] patient's anatomy" [36].

Acknowledgements-The College of Medicine of the University of Iowa supported the research for this project through a Student Research Fellowship to Kae Bendixen and funding for the History of Medicine Society, directed by Susan C. Lawrence. Kae Bendixen thanks Jon Copeland (Grinnell College) and Ron Bergman (University of Iowa) for their support on the initial inspiration for this project. We both are grateful to Teresa Mangum (University of Iowa) and the anonymous referees for their helpful comments on earlier drafts. This article is part of an on-going project to analyze the history and cultural implications of gender and medical anatomy.

\section{REFERENCES}

1. Kessler S. J. The medical construction of gender: case management of intersexed infants. Signs: J. Women Culture Society 16, 3-26, 1990.

2. Garber M. Spare parts: the surgical construction of gender. Differences: J. Feminist Cultural Stud. 1, 137-159, 1989.

3. Giacomini M., Rozee-Koker P., and Pepitone-Arreola-Rockwell F. Gender bias in human anatomy textbook illustrations. Psychol. Women Q. 10, 413420,1986 . This is the only previously published study of gender representation in 20th century anatomy texts for medical students. For their project, the authors used 8 texts published from 19731983 and concentrated on illustrations (total $N=$ 608); they did not discuss the language used in the texts.

4. Tuana N. (Ed.) Feminism and Science. Indiana University Press, Bloomington, 1989.

5. Martin E. The egg and the sperm: how science has constructed a romance based on stereotyped malefemale roles. Signs: J. Women Culture Society 16, 485-501, 1991. 
6. Fausto-Sterling A. Myths of Gender: Biological Theories about Women and Men. Basic Books, New York, 1985.

7. Martin E. The Woman in the Body: A Cultural Analysis of Reproduction. Beacon Press, Boston, 1987.

8. Hubbard R. The Politics of Women's Biology. Rutgers University Press, New Brunswick, NJ, 1990.

9. Moore K. L. Clinically Oriented Anatomy 2nd edn, p. 329. Williams and Wilkins, Baltimore, 1985.

10. Schiebinger L. Skeletons in the closet: the first illustrations of the female skeleton in eighteenth-century anatomy. In The Making of the Modern Body (Edited by Gallagher C. and Laqueur T.), pp. 4282. University of California Press, Berkeley, 1987; Page references are to those quotations cited by Schiebinger.

11. Laqueur T. Orgasm, generation and the politics of reproductive biology. In The Making of the Modern Body (Edited by Gallagher C. and Laqueur T.), pp. 1-41. University of California Press, Berkeley, 1987.

12. Aristotle Generation of Animals 737.a.27-28. Quoted in Tuana N. The Weaker Seed; The Sexist Bias of Reproductive Theory, p. 151. See Ref. [4].

13. Russett C. E. Sexual Science: The Victorian Construction of Womanhood. Harvard University Press, Cambridge, MA, 1989.

14. Crafts R. C. A Textbook of Human Anatomy 2nd edn, p. 289. Wiley, New York, 1979.

15. Woodburne R. T. Essentials of Human Anatomy, 2nd edn, p. 503. Oxford University Press, New York, 1961.

16. Woodburne R. T. Essentials of Human Anatomy, 3rd edn, p. 505. Oxford University Press, New York, 1969.

17. Basmajian J. V. (Ed.) Grant's Method of Anatomy, 10th edn, p. 234. Williams and Wilkins, Baltimore, 1980.

18. Grant J. C. B. A Method of Anatomy: Descriptive and Comparative, 5th edn, p. 322. Williams and Wilkins, Baltimore, 1952.

19. Gardner E., Gray D. and O'Rahielly R. (Eds) Anatomy: A Regional Study of Human Structure, 2nd edn, p. 459. W. B. Saunders Co., Philadelphia, 1963.

20. Gray H. Anatomy of the Human Body, 26th edn (Edited by Goss C. M.), pp. 1362-1363. Lea and Febriger, Philadelphia, 1954.
21. Lockhart L. D., Hamilton G. F. and Fyfe F. W. Anatomy of the Human Body, 1st edn, pp. 341, 516, 648. J. B. Lippincott, Philadelphia, 1959.

22. Christiansen J. B. and Talford I. R. Synopsis of Gross Anatomy, 2nd edn, p. 95. Harper and Row, Hagerstown, MD, 1972.

23. Lumley J. S. P., Craven J. L. and Aitken J. T. ESsential Anatomy and some Clinical Applications, 2nd edn, p. 133. Churchill Livingstone, New York, 1975.

24. Edwards L. F. Concise Anatomy, 2nd edn, p. 340, McGraw-Hill, New York, 1956.

25. Gardner E., Gray D. and O'Rahielly R. (Eds) Anatomy: A Regional Study of Human Structure, 1st edn, p. 291. W. B. Saunders Co., Philadelphia, 1960.

26. Schäfer E. A., Symington J., Bryce T. H. (Eds) Quain's Elements of Anatomy, 11th edn, pp. 1, 2. Longmans, Green and Co., New York, 1908.

27. Hollinshead W. H. Textbook of Anatomy, 3rd edn, p. 745. Harper and Row, Hagerstown, MD, 1974.

28. Schaeffer J. P. (Ed.) Morris' Human Anatomy, 11th edn, p. 1176. The Blakiston Company, New York, 1953.

29. Hall-Craggs E. C. B. Anatomy as a Basis for Clinical Medicine, 1st edn, p. 256. Urban and Schwarzenberg, Baltimore, 1985.

30. Grant J. C. B. and Basmajian J. V. Grant's Methods of Anatomy, 7th edn, p. 281. Williams and Wilkins, Baltimore, 1965.

31. Green J. H. and Silver J. H. S. An Introduction to Human Anatomy, 1st edn, p. 247. Oxford University Press, New York, 1981.

32. Gray H. Anatomy, Descriptive and Surgical, 13th edn, pp. 1089-90. (Edited by Pick T. P.). Lea Brothers and Co., Philadelphia, 1893.

33. Snell R. S. Clinical Anatomy for Medical Students, 1 edn, p. 291. Little, Brown and Co., Boston, 1973.

34. Lumley J. S. P., Craven J. L. and Aitken J. I. Essential Anatomy and Some Clinical Applications, 4th edn, p. 167. Churchill Livingstone, New York, 1987.

35. Lindner H. H. Clinical Anatomy, 1st edn, pp. 327, 357, 302. Appleton and Lange, Norwalk, CT, 1989.

36. Arnold, M. Reconstructive Anatomy: A Method for the Study of Human Structure, 1st edn. Forward. W. B. Saunders Co., Philadelphia, 1968. 